УДК 697.329:006.354

\title{
АСПЕКТЫ ПРОЕКТИРОВАНИЯ ЭЛЕКТРИЧЕСКИХ СХЕМ ФОТОЭЛЕКТРИЧЕСКИХ БАТАРЕЙ ДЛЯ НАЗЕМНЫХ ФОТОЭЛЕКТРИЧЕСКИХ СИСТЕМ
}

\author{
Андрианова Людмила Прокопьевна \\ д-р техн. наук, профессор \\ Хазиева Регина Тагировна \\ канд. техн. наук, доцент \\ Васильев Петр Игоревич \\ ассистент \\ Голубев Дэнис Михайлович
}

студент

Уфимский государственный нефтяной технический университет

Аннотация. В статье рассмотрены аспекты построения электрических структурных схем фотоэлектрических батарей для наземных фотоэлектрических систем. Приведены компонентный состав, классификация и варианты подключения фотоэлектрических батарей к оборудованию контура потребления. Представлены типовые электрические структурные схемы фотоэлектрических батарей с шунтирующими диодами с различным соединением фотоэлектрических элементов в фотоэлектрическом модуле: с одной фотоэлектрической цепочкой, с несколькими параллельными фотоэлектрическими цепочками, с несколькими параллельными фотоэлектрическими группами. Показаны принципы построения фотоэлектрических батарей, соединенных с устройствами преобразования энергии, имеющими несколько входов постоянного тока с подключенными устройствами слежения за точкой максимальной мощности.

Ключевые слова: фотоэлектрические батареи, фотоэлектрические модули, фотоэлектрические элементы, фотоэлектрические группы, шунтирующие диоды, устройство преобразования энергии, слежение за точкой максимальной мощности. 


\title{
ASPECTS OF DESIGNING ELECTRICAL CIRCUITS OF PHOTOVOLTAIC BATTERIES FOR GROUND-BASED PHOTOVOLTAIC SYSTEMS
}

\author{
Andrianova Lyudmila Prokopyevna \\ Khazieva Regina Tagirovna \\ Vasiliev Pyotr Igorevich \\ Golubev Denis Mikhailovich
}

\begin{abstract}
The article discusses aspects of the construction of electrical structural schemes of photovoltaic batteries for ground-based photovoltaic systems. The component composition, classification and options for connecting photovoltaic batteries to the equipment of the consumption circuit are given. Typical electrical block diagrams of photovoltaic batteries with shunt diodes with various connections of photovoltaic cells in a photovoltaic module are presented: with one photovoltaic circuit, with several parallel photovoltaic circuits, with several parallel photovoltaic groups. The principles of construction of photovoltaic batteries connected to energy conversion devices having several DC inputs with connected devices for tracking the maximum power point are shown.
\end{abstract}

Key words: photovoltaic batteries, photovoltaic modules, photovoltaic cells, photovoltaic groups, shunt diodes, energy conversion device, tracking the maximum power point.

\section{Назначение и типы фотоэлектрических батарей в фотоэлектрической системе}

«Фотоэлектрическая батарея (ФБ) - устройство, состоящее из электрически соединенных фотоэлектрических модулей (ФМ), фотоэлектрических цепочек (ФЦ) или фотоэлектрических групп (ФГ), генерирующее постоянный электрический ток под воздействием электромагнитного излучения и включающее также все компоненты, обеспечивающие электрические и механические соединения внутри батареи и с внешними устройствами, конструкциями» [1, с. 5].

К ФБ относятся все ее компоненты до входных зажимов постоянного тока преобразователя энергии, накопители энергии или нагрузки постоянного тока, а границей ФБ считается выходная сторона отключающего устройства ФБ. 
ФБ может состоять из одного ФМ, отдельной ФЦ, или нескольких параллельно соединенных ФЦ, или нескольких параллельно соединенных ФГ и их соответствующих компонентов. ФБ является основой фотоэлектрических систем постоянного тока (ФЭС), предназначенных для обеспечения электроэнергией цепей потребителя (рис. 1).

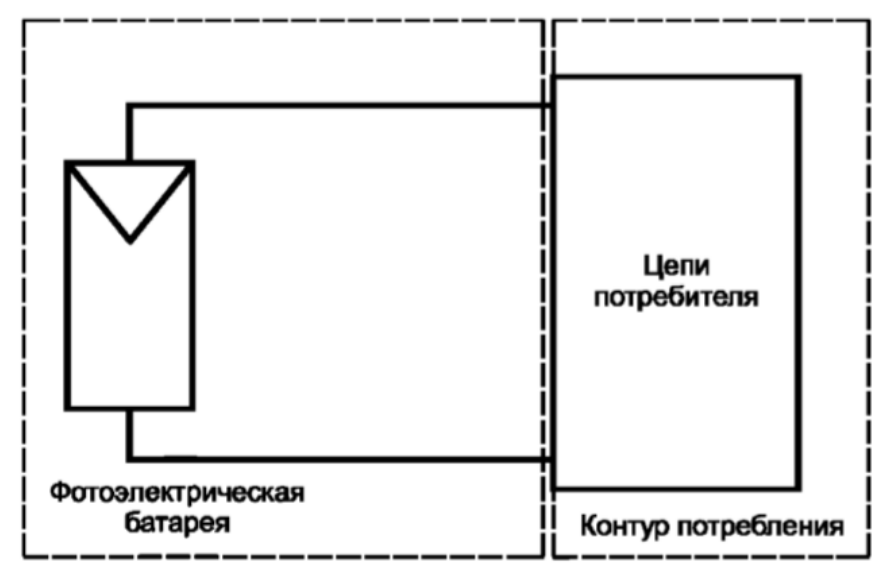

\section{Рис. 1. Общая функциональная схема ФЭС [1, с.10]}

Фотоэлектрические батареи (ФБ) в зависимости от варианта цепи потребления в соответствии с ГОСТ 56978 [1] подразделяются на следующие типы:

1) ФБ, подключенная к нагрузке постоянного тока, которая может содержать устройство накопления энергии;

2) ФБ, подключенная к устройству накопления энергии: аккумуляторная батарея (АБ) или иные аналогичные устройства;

3) ФБ, подключенная к устройствам (цепям) переменного тока, в частности к электрораспределительной сети, через преобразующее оборудование, которое содержит простое разделение;

4) ФБ, подключенная к устройствам (цепям) переменного тока, через преобразующее оборудование, которое не содержит простого разделения;

5) ФБ смешанного подключения к нескольким из первых четырех типов оборудования.

Варианты подключения фотоэлектрических батарей к оборудованию контура потребления показаны на рис. 2. 


\section{СТРАТЕГИЧЕСКИЙ ПОТЕНЦИАЛ ПЕРСПЕКТИВНЫХ

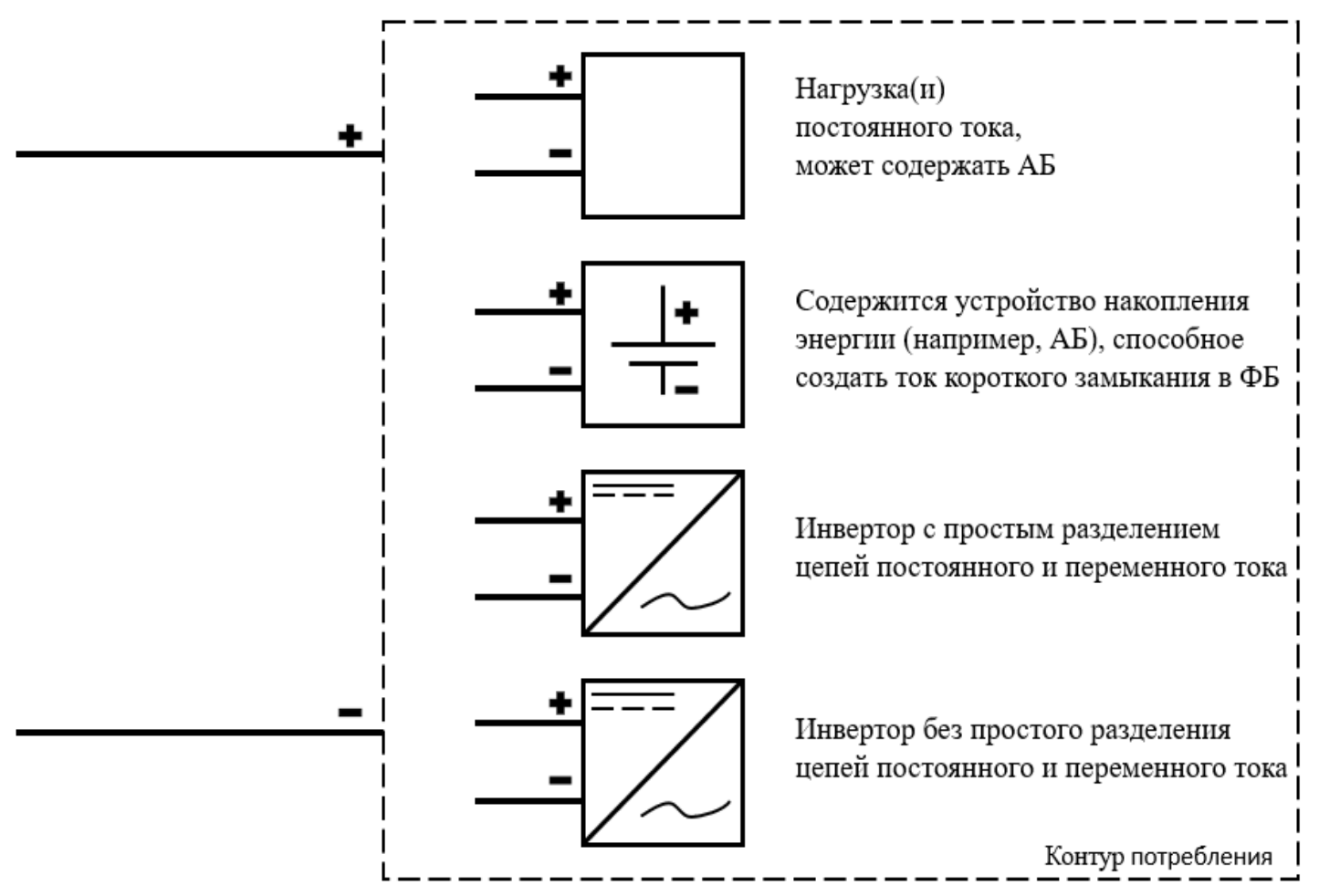

\section{Рис. 2. Варианты цепей потребителя ФБ [1, с.10]}

К устройствам контура потребления ФБ относятся:

1) Устройство преобразования энергии (УПЭ, в котором происходит преобразование производимой фотоэлектрической батареей электрической энергии постоянного тока в энергию с необходимыми частотой и/или напряжением для питания нагрузки, или накопления в аккумуляторной батарее, или передачи в сеть;

2) Устройство преобразования энергии с разделением цепей (УПЭ с разделением цепей) - это устройство преобразования энергии с простым разделением выходных цепей контура потребления и контура ФБ, имеющее токи утечки, не превышающие предельных значений, установленных для УПЭ, классифицируемых как УПЭ с разделением цепей.

Термин «УПЭ с разделением цепей» применяется для обозначения УПЭ с разделением выходного контура электрораспределительной сети и контура ФБ.

Простое разделение означает разделение между цепями или между цепью и землей посредством основной изоляции токоведущих частей, обеспечивающей в том числе защиту от прямого прикосновения [1, с.7]. 


\section{СТРАТЕГИЧЕСКИЙ ПОТЕНЦИАЛ ПЕРСПЕКТИВНЫХ РАЗРАБОТОК И ИССЛЕДОВАНИЙ}

Разделение может быть выполнено как часть УПЭ или снаружи УПЭ с помощью специальных средств или устройств разделения, например, инвертор с внешним изолирующим трансформатором. Если разделение выполнено снаружи УПЭ, в контуре «УПЭ - специальные средства или устройства разделения» не должно быть подключено никакого иного оборудования.

В УПЭ, к которому подключена более чем одна цепь контура потребления, разделение может быть выполнено между некоторыми цепями и контуром ФБ и отсутствовать между другими цепями и ФБ. Например, в инверторе, соединенном с ФБ, аккумуляторной батареей (АБ) и электрораспределительной сетью, разделение может быть выполнено между контуром ФБ и контуром электрораспределительной сети и отсутствовать между контурами фотоэлектрической батареи и аккумуляторной батареи.

Если в УПЭ отсутствует внутреннее разделение выходного контура электрораспределительной сети и контура ФБ, но для этого используются специальные средства или устройства разделения, такое сочетание УПЭ и специальных средств или устройства разделения может рассматриваться как УПЭ с разделением цепей.

Устройство преобразования энергии без разделения цепей (УПЭ без разделения цепей) - устройство преобразования энергии без минимального разделения выходных цепей контура потребления и контура ФБ или имеющее токи утечки, превосходящие требуемые для УПЭ с разделением цепей.

Слежение за точкой максимальной мощности (СТMМ) метод управления, обеспечивающий работу ФБ в окрестности точки вольт-амперной характеристики (BAX), в которой произведение значений тока и напряжения максимально и, следовательно, максимальна выходная мощность ФБ при заданных рабочих условиях.

\section{Электрические структурные схемы фотоэлектрических батарей}

Вариант электрической схемы ФБ, состоящей из одной фотоэлектрической цепочки (ФЦ), показан на рис. 3. 


\section{СТРАТЕГИЧЕСКИЙ ПОТЕНЦИАЛ ПЕРСПЕКТИВНЬХ РАЗРАБОТОК И ИССЛЕДОВАНИЙ}

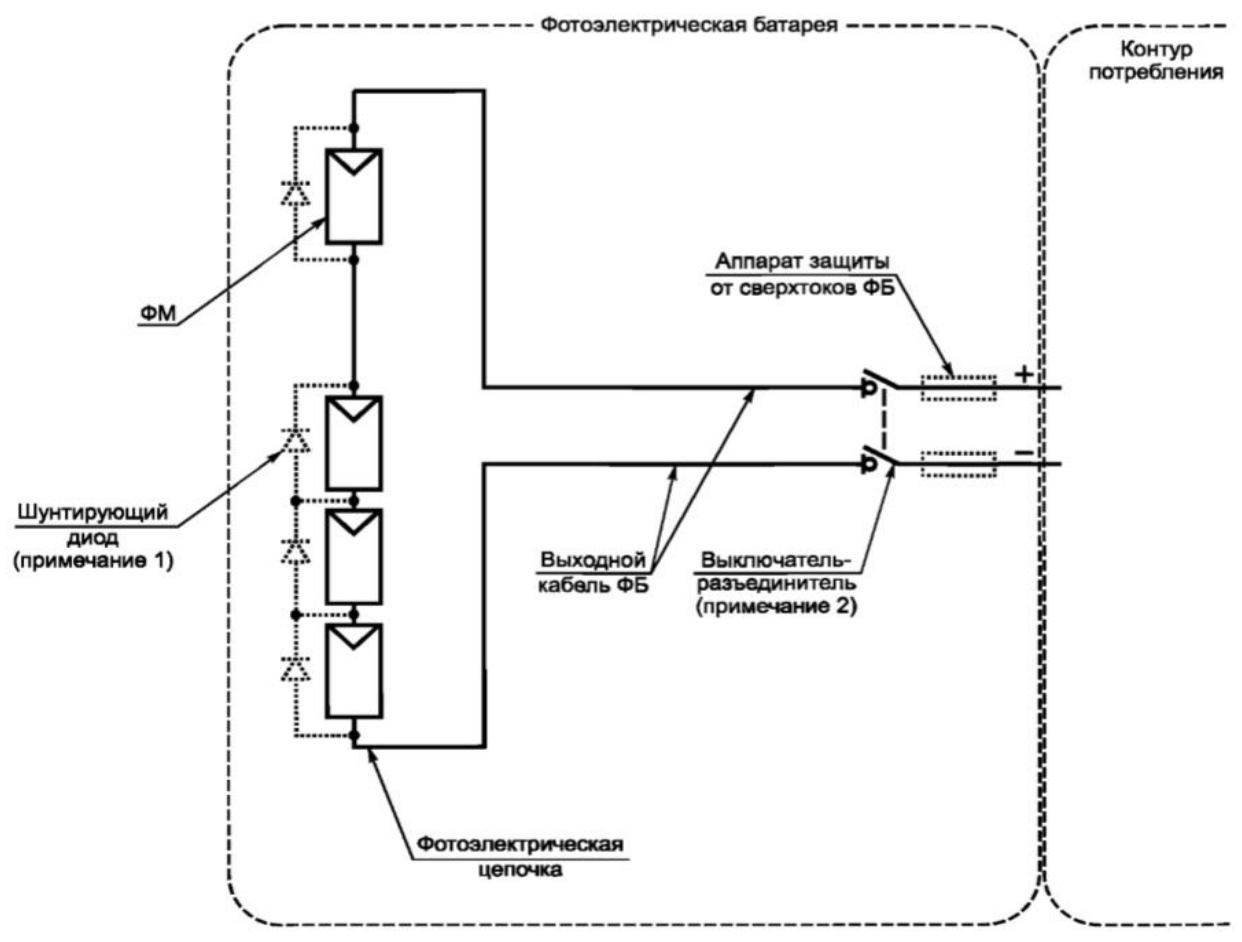

Рис. 3. Схема фотоэлектрической батареи с одной цепочкой [1, с.11]:

\begin{tabular}{|l|l|}
\hline $\begin{array}{l}\text { ФМ - } \\
\text { Фотоэлектрический }\end{array}$ & $\begin{array}{l}\text { Устройство, конструктивно объединяющее электрически } \\
\text { соединенные между собой ФЭ, защищенное от окружающей среды } \\
\text { и допускающее испытания и эксплуатацию в качестве независимой } \\
\text { конструкционной единицы. }\end{array}$ \\
\hline $\begin{array}{l}\text { Фотоэлектрический } \\
\text { элемент (ФЭ) }\end{array}$ & $\begin{array}{l}\text { Наименьший неделимый преобразователь энергии солнечного } \\
\text { излучения в электрическую энергию на основе фотоэффекта. }\end{array}$ \\
\hline $\begin{array}{l}\text { Фотоэлектрическая } \\
\text { цепочка (ФЦ) }\end{array}$ & $\begin{array}{l}\text { Последовательное электрическое соединение двух или более } \\
\text { фотоэлектрических компонентов (ФК): ФМ, ФГ одного уровня в } \\
\text { ФБ. }\end{array}$ \\
\hline $\begin{array}{l}\text { Шунтирующий диод } \\
\text { Диод, установленный по направлению тока параллельно одному или } \\
\text { нескольким последовательно соединенным ФЭ в ФМ или ФМ в Фц, } \\
\text { и обеспечивающий обход током разрыва цепи, поврежденных и } \\
\text { затененных ФЭ или ФМ. }\end{array}$ \\
\hline $\begin{array}{l}\text { Выходной кабель } \\
\text { фотоэлектрической } \\
\text { батареи }\end{array}$ & $\begin{array}{l}\text { Кабель фотоэлектрической батареи, по которому протекает } \\
\text { выходной ток от фотоэлектрической батареи. }\end{array}$ \\
\hline $\begin{array}{l}\text { Выключатель- } \\
\text { разъединитель }\end{array}$ & $\begin{array}{l}\text { Выключатель, который в отключенном положении удовлетворяет } \\
\text { требованиям по изоляции, нормированным для разъединителя. }\end{array}$ \\
\hline $\begin{array}{l}\text { Аппарат защиты от } \\
\text { сверхтока ФБ }\end{array}$ & $\begin{array}{l}\text { Аппарат, предназначенный для прерывания электрической цепи в } \\
\text { случае, если ток в цепи превышает установленные значения в } \\
\text { течение определенной длительности. (На схеме показан } \\
\text { предохранитель) }\end{array}$ \\
\hline
\end{tabular}




\section{СТРАТЕГИЧЕСКИЙ ПОТЕНЦИАЛ ПЕРСПЕКТИВНЬХ РАЗРАБОТОК И ИССЛЕДОВАНИЙ}

Вариант схемы ФБ с несколькими параллельными ФЦ показан на рис. 4.

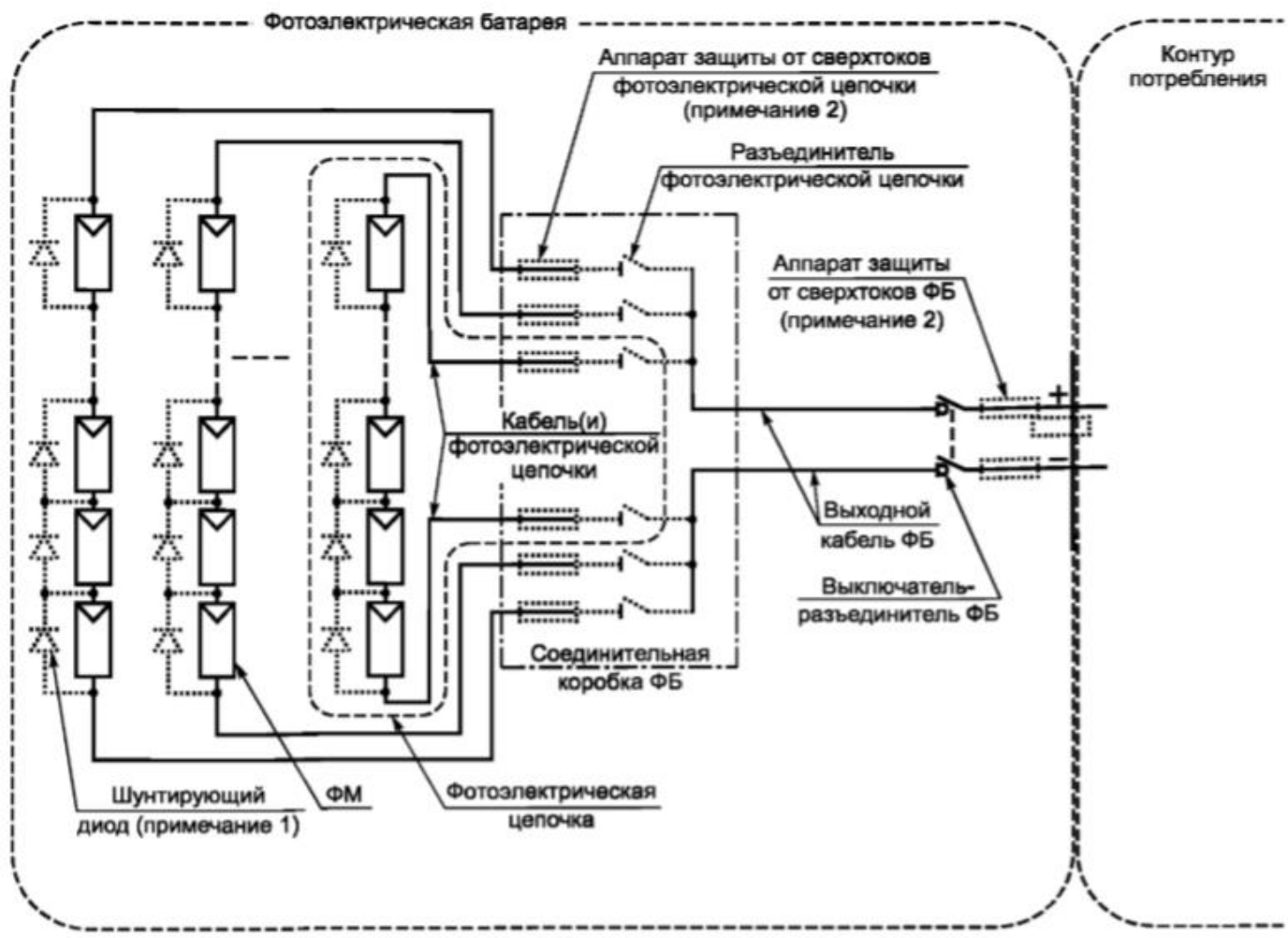

\section{Рис. 4. Схема фотоэлектрической батареи с несколькими параллельными цепочками [1, с. 12]:}

\begin{tabular}{|l|l|}
\hline $\begin{array}{l}\text { Фотоэлектрическая } \\
\text { цепоча (ФЦ) }\end{array}$ & $\begin{array}{l}\text { Последовательное электрическое соединение двух или более } \\
\text { фотоэлектрических компонентов (ФК): ФМ, ФГ одного уровня в } \\
\text { ФБ. } \\
\begin{array}{l}\text { Аппарат защиты от } \\
\text { фотоэлектрической } \\
\text { цепочки }\end{array}\end{array} \quad \begin{array}{l}\text { Аппарат, предназначенный для прерывания электрической цепи в } \\
\text { случае, если ток в цепи превышает установленные значения в } \\
\text { течение определенной длительности. } \\
\text { (На схеме показан предохранитель) }\end{array}$ \\
\hline $\begin{array}{l}\text { Разъединитель } \\
\text { фотоэлектрической } \\
\text { цепочки }\end{array}$ & $\begin{array}{l}\text { Контактный коммутационный аппарат, в разомкнутом } \\
\text { положении соответствующий требованиям к функции } \\
\text { разъединения. }\end{array}$ \\
\hline $\begin{array}{l}\text { Кабель } \\
\text { фотоэлектрической } \\
\text { цепочки }\end{array}$ & $\begin{array}{l}\text { Кабель, соединяющий фотоэлектрические модули } \\
\text { (фотоэлектрические компоненты ФБ) в фотоэлектрическую } \\
\text { цепочку и выходящий из фотоэлектрической цепочки. }\end{array}$ \\
\hline $\begin{array}{l}\text { Соединительная коробка } \\
\text { ФБ }\end{array}$ & $\begin{array}{l}\text { Коммутационная коробка, в которой соединяются кабели } \\
\text { фотоэлектрических групп или кабели фотоэлектрических(ой) } \\
\text { цепочек(ки), если ФБ состоит только из фотоэлектрических(ой) } \\
\text { цепочек(ки), которая может включать устройства защиты от } \\
\text { сверхтоков, а также другие аппараты защиты и выключатели- } \\
\text { разъединители и из которой выходит выходной кабель ФБ. }\end{array}$ \\
\hline
\end{tabular}




\section{СТРАТЕГИЧЕСКИЙ ПОТЕНЦИАЛ ПЕРСПЕКТИВНЬХ

Схема фотоэлектрической батареи $\mathrm{c}$ несколькими параллельными фотоэлектрическими группами (ФГ), состоящими из нескольких параллельных фотоэлектрических цепочек, изображена на рис. 5.

Фотоэлектрическая группа на схеме фотоэлектрической батареи, изображенная на рис. 5, состоит из однотипных модулей.

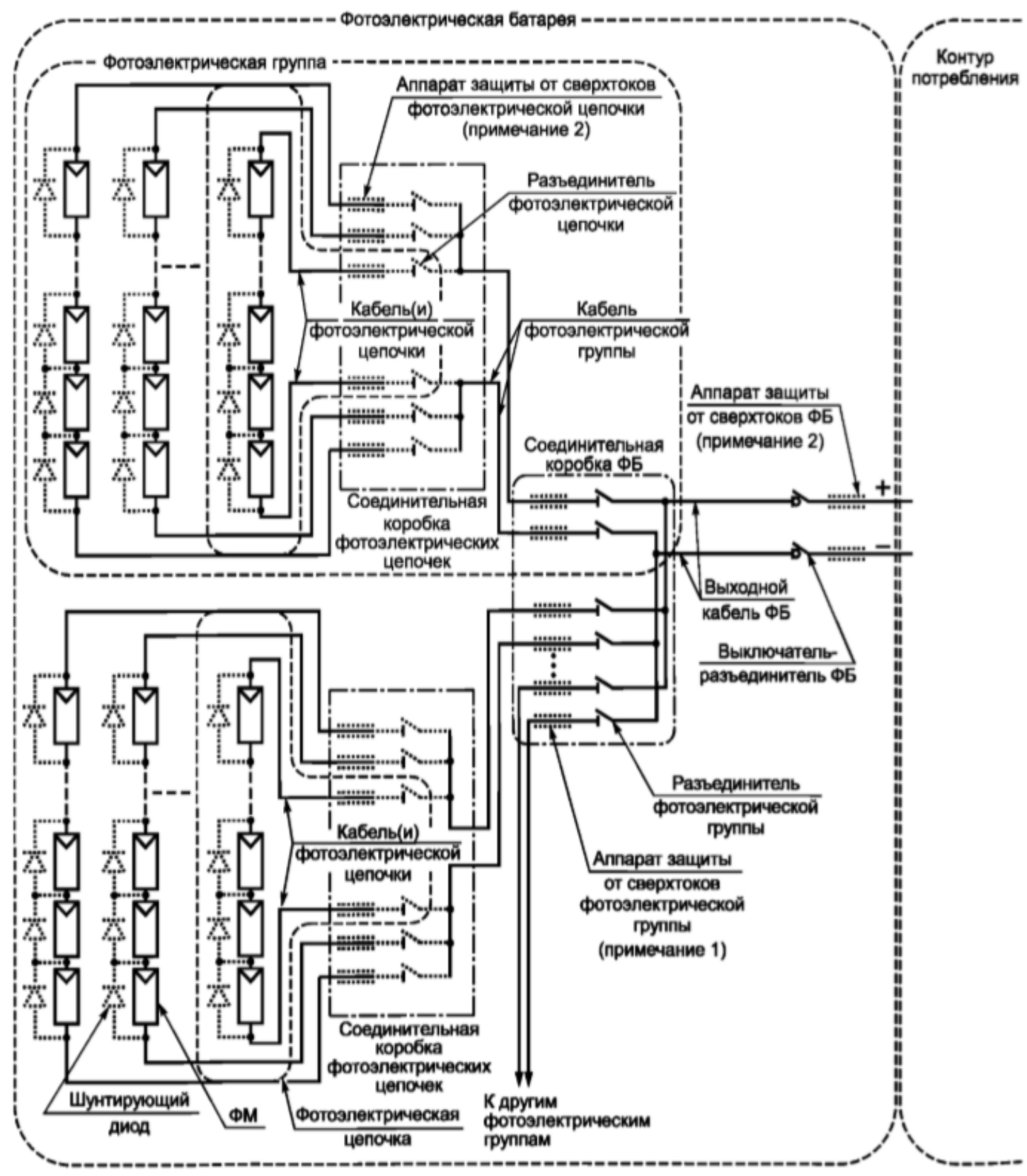

Рис. 5. Схема фотоэлектрической батареи с несколькими параллельными фотоэлектрическими группами, состоящими из нескольких параллельных фотоэлектрических цепочек [1, c.13]: 


\section{СТРАТЕГИЧЕСКИЙ ПОТЕНЦИАЛ ПЕРСПЕКТИВНЫХ РАЗРАБОТОК И ИССЛЕДОВАНИЙ}

\begin{tabular}{|c|c|}
\hline $\begin{array}{l}\text { Фотоэлектрическая } \\
\text { цепочка (ФЦ) }\end{array}$ & $\begin{array}{l}\text { Последовательное электрическое соединение двух или более } \\
\text { фотоэлектрических компонентов (ФК): ФМ, ФГ одного уровня } \\
\text { в ФБ. }\end{array}$ \\
\hline Фотоэлектрическая группа & $\begin{array}{l}\text { Часть ФБ, состоящая из электрически параллельно } \\
\text { соединенных фотоэлектрических компонентов ФК } \\
\text { (ФЦ или ФГ предыдущих уровней, более удаленных от выхода } \\
\text { ФБ). }\end{array}$ \\
\hline $\begin{array}{l}\text { Фотоэлектрический } \\
\text { компонент ФБ (ФК): }\end{array}$ & $\begin{array}{l}\text { Фотоэлектрический модуль (ФМ), или фотоэлектрическая } \\
\text { цепочка (ФЦ), или фотоэлектрическая группа (ФГ) } \\
\text { фотоэлектрической батареи (ФБ). }\end{array}$ \\
\hline $\begin{array}{l}\text { Кабель } \\
\text { фотоэлектрической } \\
\text { группы }\end{array}$ & $\begin{array}{l}\text { Выходной кабель от фотоэлектрической группы, по которому } \\
\text { протекает выходной ток соответствующей группы } \\
\text { фотоэлектрической батареи. }\end{array}$ \\
\hline $\begin{array}{l}\text { Соединительная коробка } \\
\text { фотоэлектрических } \\
\text { цепочек }\end{array}$ & $\begin{array}{l}\text { Коммутационная коробка, в которой соединяются } \\
\text { фотоэлектрические цепочки и которая может включать } \\
\text { устройства защиты от сверхтоков, а также другие аппараты } \\
\text { защиты и аппараты/устройства коммутации. }\end{array}$ \\
\hline $\begin{array}{l}\text { Соединительная коробка } \\
\text { фотоэлектрической } \\
\text { группы: }\end{array}$ & $\begin{array}{l}\text { Коммутационная коробка, в которой соединяются } \\
\text { фотоэлектрические группы предыдущего уровня, кроме } \\
\text { последнего, и которая может включать устройства защиты от } \\
\text { сверхтоков, а также другие аппараты защиты и } \\
\text { аппараты/устройства коммутации. }\end{array}$ \\
\hline $\begin{array}{l}\text { Разъединитель } \\
\text { фотоэлектрической } \\
\text { группы }\end{array}$ & $\begin{array}{l}\text { Контактный коммутационный аппарат, в разомкнутом } \\
\text { положении соответствующий требованиям к функции } \\
\text { разъединения. }\end{array}$ \\
\hline $\begin{array}{l}\text { Аппарат защиты от } \\
\text { сверхтоков } \\
\text { фотоэлектрической } \\
\text { группы }\end{array}$ & $\begin{array}{l}\text { Аппарат, предназначенный для прерывания электрической цепи } \\
\text { в случае, если ток в цепи превышает установленные значения в } \\
\text { течение определенной длительности. (предохранители) }\end{array}$ \\
\hline
\end{tabular}

Пояснения к схеме (рис. 5). Разные ФГ в ФБ могут состоять из ФМ, изготовленных по разным технологиям, но с одинаковыми выходными электрическими характеристиками.

Если ФБ включает ФГ нескольких уровней, это требование относится к ФГ первого, наиболее удаленного от выхода ФБ, уровня.

В некоторых системах кабель ФБ отсутствует, и все ФЦ или ФГ могут соединяться в соединительной коробке, устанавливаемой на устройстве преобразования энергии (УПЭ), или подключаться непосредственно ко входам устройств контура потребления. Фотоэлектрические группы последнего уровня, на выходе ФБ могут соединяться непосредственно в УПЭ. 


\section{СТРАТЕГИЧЕСКИЙ ПОТЕНЦИАЛ ПЕРСПЕКТИВНЬХ

Подключение фотоэлектрической батареи к УПЭ с несколькими входами постоянного тока

Фотоэлектрическая батарея может присоединяться в фотоэлектрической системе к УПЭ с несколькими входами постоянного тока без соединительной коробки (см. рис. 6, 7).

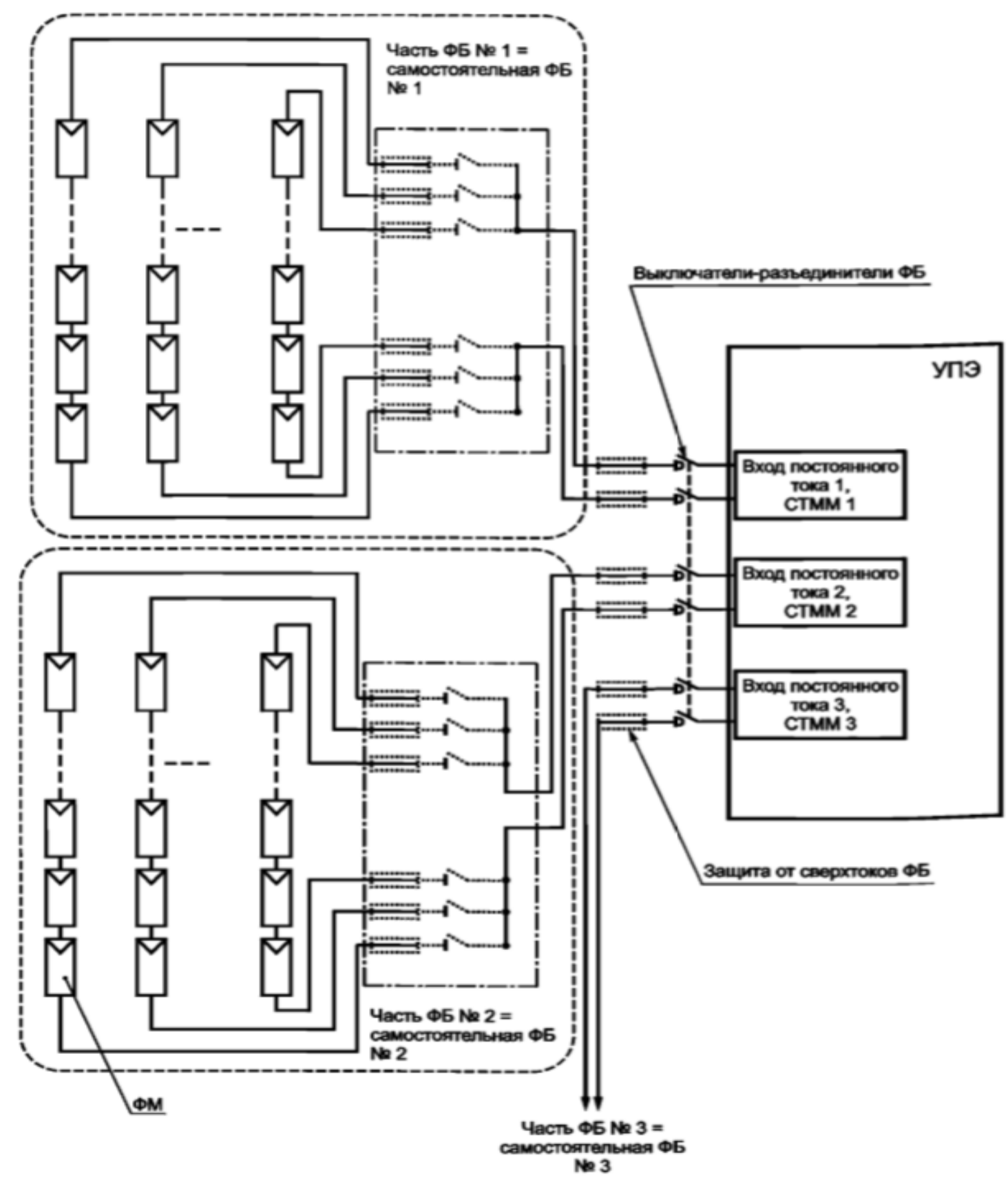

Рис. 6. Фотоэлектрическая батарея, соединенная с УПЭ со входами постоянного тока, к которым подключены устройства слежения за точкой максимальной мощности [1] 


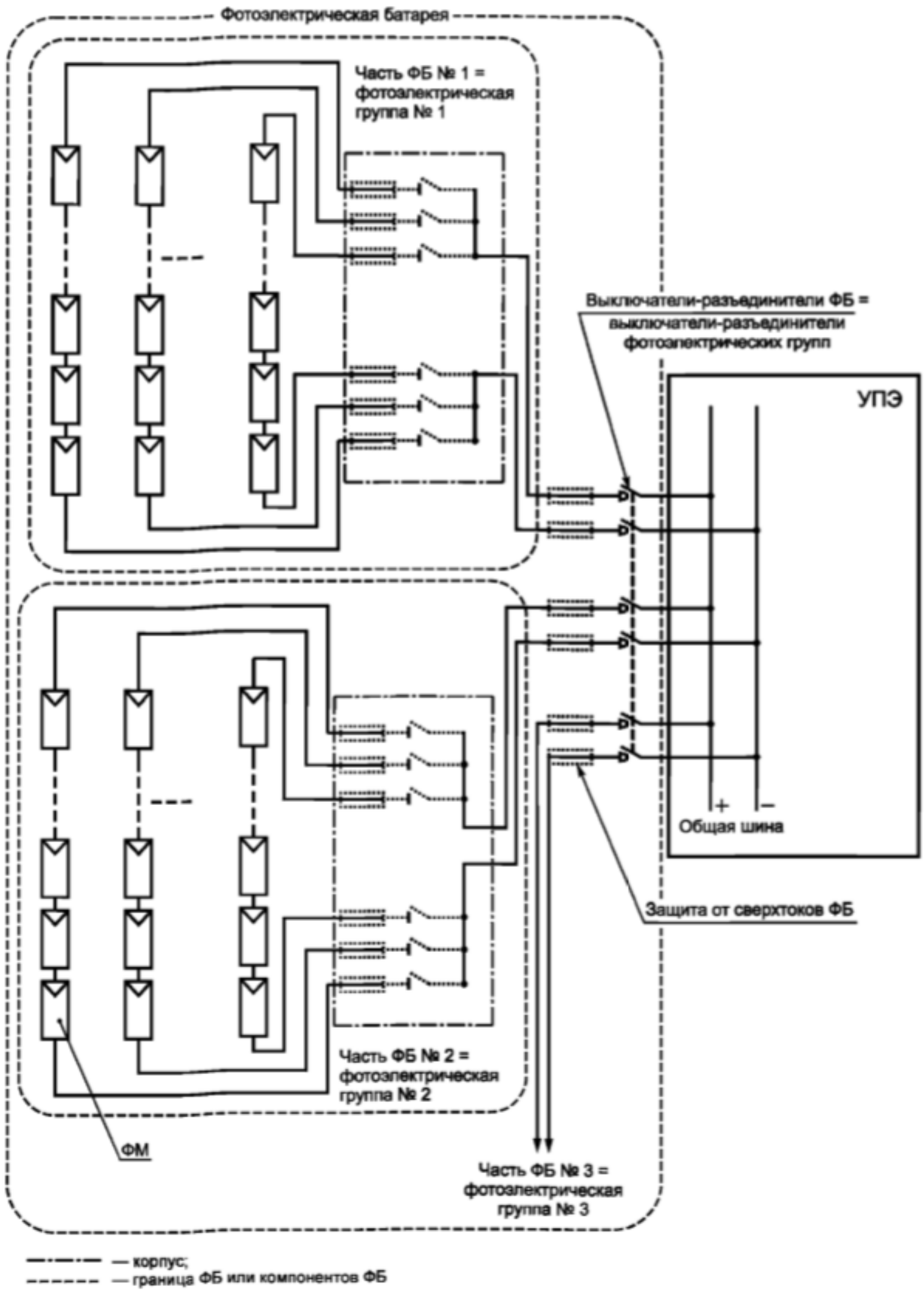

Рис. 7. Фотоэлектрическая батарея, подключенная к УПЭ со входами постоянного тока, присоединенными к общей шине внутри УПЭ [1] 


\section{СТРАТЕГИЧЕСКИЙ ПОТЕНЦИАЛ ПЕРСПЕКТИВНЬХ РАЗРАБОТОК И ИССЛЕДОВАНИЙ}

В этом случае защита от сверхтоков и выбор сечений проводников для каждой части ФБ, подключенной к отдельному входу УПЭ, зависит от ограничения всех обратных токов из УПЭ в фотоэлектрическую батарею.

На входах УПЭ подключены устройства слежения за точкой максимальной мощности (CTMM). В тех случаях, когда в УПЭ на входах подключены устройства СТММ (рис. 6), при выборе защиты от сверхтоков частей ФБ, которые соединены с этими входами, следует учитывать все возможные обратные токи, определяемые в соответствии с требованиями [1]. В этом случае при проектировании ФБ каждая часть ФБ, соединенная с таким входом УПЭ, может рассматриваться как самостоятельная фотоэлектрическая батарея.

Для обеспечения отключения от УПЭ каждая такая самостоятельная ФБ должна быть подключена к входам УПЭ через выключатель-разъединитель. Все выключатели-разъединители должны быть спарены и срабатывать одновременно, на каждом должна быть установлена предупреждающая маркировка. Входы УПЭ соединены общей шиной внутри УПЭ. В тех случаях, когда несколько входов УПЭ соединены внутри УПЭ параллельно общей шиной постоянного тока, как показано на рис. 7, каждая часть ФБ, соединенная с одним входом, должна рассматриваться при проектировании ФБ как фотоэлектрическая группа. Объединение всех таких ФГ считается полной ФБ. Для обеспечения отключения от УПЭ каждая такая ФГ должна быть подключена к входам УПЭ через выключатель-разъединитель.

\section{Заключение}

Представленные в статье схемы подключения фотоэлектрических батарей к оборудованию контура потребления построены с учетом нормативных требований электробезопасности ФБ. В этих схемах предусмотрены аппараты защиты от сверхтоков для фотоэлектрических модулей, фотоэлектрических цепочек, фотоэлектрических групп и в целом фотоэлектрической батареи.

\section{Список литературы}

1. ГОСТР 56978-2016 (IEC/TS 62548:2013) Батареи фотоэлектрические. Технические условия (IEC/TS 62548:2013, Photovoltaic (PV) arrays — Design requirements, MOD) /введ. Впервые 27.06.2016; акт. 01.01.2021. - Москва: Стандартинформ, 2016. - 77 c. 
2. ГОСТ Р 57229-2016 (МЭК 62817: 2014) Системы фотоэлектрические Устройства слежения за Солнцем. Технические условия. Photovoltaic systems. Solar trackers. General specifications / введ. впервые 01.09.2017; акт. 01.01.2021. Москва: Стандартинформ, 2016. - 62 с.

3. ГОСТ Р 50571.7.712 - 2013/ МЭК 60364-7-712 2002 Электроустановки низковольтные. Требования к специальным электроустановкам или местам их расположения. Системы питания с использованием фотоэлектрических (ФЭ) солнечных батарей. Часть 7-712 / введ. впервые 01.01.2015; акт. 01.01.2021. Москва: Стандартинформ, 2014. - 14 с.

4. ГОСТР 57230- 2016 (МЭК 62852:2014) Системы фотоэлектрические. Соединители постоянного тока. Классификация, требования к конструкции и методы испытаний (IEC 62852:2014, Connectors for DC-application in photovoltaic systems - Safety requirements and tests, MOD) / введ. впервые 01.01.2017; акт. 01.01.2021. - Москва: Стандартинформ, 2016. - 58 с.

() Л.П. Андрианова, Р.Т. Хазиева, П.И. Васильев, Д.М. Голубев, 2021 